\title{
Validation of an Accelerometer Index to measure physical activity among Brazilian adolescent girls
}

\author{
Validação de um índice de acelerômetro para medir a atividade física entre adolescentes brasileiras \\ Validación de un índice acelerómetro para medir la actividad física entre las adolescentes brasileñas
}

Karin Louise Lenz Dunker ${ }^{1}$,Timóteo Leandro Araujo², Sandra Marcela Mahecha ${ }^{3}$, Paula Costa Teixeira ${ }^{4}$

\begin{abstract}
Objective: This investigation aimed to psychometrically validate an accelerometer index against a self-reported questionnaire in a sample of female adolescents. Methods: This analysis was based on a multicentric prospective randomized controlled trial among adolescent girls aged 12 to 14 years. Accelerometer devices were given to participants to be worn on their person for seven consecutive days, after completing a self-administered questionnaire. The "Brazilian Economic Classification" was used to rank participants according to socioeconomic strata. Results: There were 195 participants with an average age of $13.4 \pm 0.65$ years, $10.8 \%$ obese and $51 \%$ physically inactive. Participants in the medium-high class were less physically active. The participants in mediumlow class presented higher METs $[1.03( \pm 0.03)]$. Exploratory factor analysis demonstrated a two-factor structure, labeled Daily Physical Activity and Sedentary Activity, with good factor loadings and internal reliability scores, as well as appropriate validity across a range of self-reported physical activity measures. Conclusion: Results allow us to reflect about the use of instruments to evaluate interventions directed to weight related problems.
\end{abstract}

Keywords: Accelerometry, Physical Activity Assessment, Adolescent, Validity.

\section{RESUMO}

Objetivo: Este estudo teve como objetivo validar psicometricamente um índice de acelerômetro com um questionário de auto relato em uma amostra de adolescentes do sexo feminino. Métodos: Esta análise foi baseada em um estudo prospectivo randomizado multicêntrico controlado entre adolescentes de 12 a 14 anos. Dispositivos de acelerômetro foram dados as participantes para serem usados por sete dias consecutivos, após completar um questionário auto preenchido. A "Classificação Econômica Brasileira" foi usada para classificar os participantes de acordo com os estratos socioeconômicos. Resultados: 195 participantes com idade média de 13,4 \pm 0,65 anos, participaram do estudo sendo $10,8 \%$ obesos e $51 \%$ fisicamente inativos. Os participantes da classe média-alta eram menos ativos fisicamente. Os participantes da classe média-baixa apresentaram maiores METs [1,03 $( \pm 0,03)]$. A análise fatorial exploratória demonstrou uma estrutura de dois fatores, denominada Atividade Física Diária e Atividade Sedentária, com boas cargas fatoriais e escores de confiabilidade interna, bem como validade apropriada em uma série de medidas de atividade física auto referidas. Conclusão: Os resultados permitem refletir sobre o uso de instrumentos para avaliar intervenções direcionadas a problemas relacionados ao peso.

Palavras-chave: Acelerometria, Avaliação de Atividade Física, Adolescente, Validação.

\footnotetext{
${ }^{1}$ Departamento de Psiquiatria e Psicologia Médica da Universidade Federal de São Paulo - SP, Brazil.

2 Centro de Estudos do Laboratório de Aptidão Física de São Caetano do Sul - SP, Brazil.

3 Facultad Ciencias, Universidad Mayor, Santiago, Chile.

4 Instituto de Psiquiatria da Universidade de São Paulo (AMBULIM - IPq-HC-FMUSP) - SP, Brazil.

*E-mail: kdunker00@yahoo.com.br
}

This work was supported by the São Paulo Research Foundation (FAPESP) and by the Brazilian National Council for Scientific and Technological Development (CNPQ). 


\section{RESUMEN}

Objetivos: Esta investigación tuvo como objetivo validar psicométricamente un índice de acelerómetro frente a un cuestionario autoinformado en una muestra de mujeres adolescentes. Métodos: Este análisis se basó en un ensayo controlado aleatorizado prospectivo multicéntrico entre adolescentes de 12 a 14 años. Se administraron dispositivos acelerómetros a los participantes para que se los usen durante siete días consecutivos, después de completar un cuestionario autoadministrado. La "Clasificación Económica Brasileña" se utilizó para clasificar a los participantes según los estratos socioeconómicos. Resultados: Hubo 195 participantes con una edad promedio de $13.4 \pm 0.65$ años, $10.8 \%$ obesos y $51 \%$ físicamente inactivos. Los participantes en la clase media alta eran menos activos físicamente. Los participantes en clase media-baja presentaron MET más altos [1.03 ( \pm 0.03$)]$. El análisis factorial exploratorio demostró una estructura de dos factores, denominada actividad física diaria y actividad sedentaria, con buenas cargas de factor y puntajes de confiabilidad interna, así como la validez apropiada en un rango de medidas de actividad física autoinformadas. Conclusión: Los resultados nos permiten reflexionar sobre el uso de instrumentos para evaluar intervenciones dirigidas a problemas relacionados con el peso.

Palabras clave: Acelerometría, Evaluación De Actividad Física, Adolescente, Validez.

\section{INTRODUCTION}

The rise of weight-related problems, like obesity and eating disorders among adolescent girls (DUMITH et al., 2011; VANDER WAL, 2012) highlights the importance of promoting interventions that address these issues (TODD et al., 2015). Of the potential interventions designed to promote a healthy weight, increasing physical activity (PA) through education has been the focus of program developers. The benefits of these type of interventions are numerous (HEATH et al., 2012).

However, accurately measuring adherence to PA remains challenging. Unlike other interventions where compliance can be readily assessed through objective measurements, exercise has traditionally been monitored through self-reported measures (HOLLIS et al., 2017). Self-reported measures, however, can generate unreliable estimates as they are often influenced by a recall and other forms of bias. Accelerometers represent a possibility of objective measurements to determine adherence to physical activity (TROIANO et al.,2012). Their ability to monitor movement patterns can also be directly connected to the measure of energy expenditure (LEE e SHIROMA, 2014). Although accelerometers have been previously validated against selfreported questionnaires in adult populations (DYRSTAD et al., 2014; LONEY et al., 2011; PRINCE et al.,2008), a limited amount of information is available regarding the validation of this metric in adolescent populations and studies present a meager sample size (CORDER et al, 2009; HALLAL et al.,2013; PHILIPPAERTS et al.,2006). Moreover, these validation studies rely on pre-specified threshold values for accelerometer-derived counts per minute rather than initially using numeric variables to determine cut-off points later. Well-designed studies are therefore currently needed to validate properly-validated measures of physical activity using accelerometer metrics.

To analyze whether accelerometer-derived data are trustworthy and to propose a new scale associated with PA, the objective of this study is to psychometrically validate an accelerometer index against a selfreported questionnaire in a sample of female adolescents, and to provide evidence of the beneficial role of combining self-reported and objective measures.

\section{METHODS}

For the current study we made use of a cohort from a prospective randomized controlled study aimed at preventing weight-related problems among adolescent girls allocated to the intervention and control groups from ten public schools from the Central-South area of São Paulo city. The design and procedure have been described in detail elsewhere (DUNKER e CLAUDINO, 2018).

The Institutional Review Board of the Federal University of São Paulo, Brazil approved our study. Informed assent and consent forms were obtained from adolescents and their parents/guardians, respectively, before the implementation of any study protocol. The trial was registered at the Brazilian Registry of Clinical Trials in September 2015 (registration number: RBR-6ddpb3). 
We considered responses to a self-reported questionnaire using non-standardized questions related to a chosen physical activity among all participants in both arms. This study is described per the STROBE (STrengthening the Reporting of OBservational studies in Epidemiology) guidelines (VON ELM et al.,2007).

After the completion of the self-reported questionnaire, participants were provided with accelerometer devices (GT3x, ActiGraph). Subjects were instructed to fasten the elastic tape to their hips while keeping the instrument on their right side, using it for seven consecutive days and only removing it while showering. Data extraction and validation were conducted using the Actilife software.

The study sample included adolescent girls aged 12 to 14 years who practiced less than one daily hour of physical activity at the time of study recruitment. Potential participants were screened through a structured questionnaire. We only included subjects who made use of the accelerometer during the study period.

The "Brazilian Economic Classification" was used to rank students according to socioeconomic strata. The sum of these scores determines the family's economic class, ranging from A1 (best income) to $E$ (worst income) (ABEP, 2008). For analysis purposes, we generated a dichotomous classification, the medium-high category comprising economic classes A2, B1, and B2, while all others were classified as part of the mediumlow category (BECKER et al., 2011).

The following accelerometer-related measures of physical activity were evaluated as potential components of our index: (1) Metabolic equivalents (METs), which indicate the rate of energy expenditure at rest. (2) The total number of Freedson activity bouts, total time spent in bouts, total count level of bouts measures. (3) The number of sedentary bouts, the total time for all sedentary bouts, and bout length including multiple bouts. (4) The total number of sedentary breaks, or the number of breaks between sedentary activities, as well as total time and length of the break. (5) The length of sedentary time. (6) The length of time spent on light intensity physical activity (PA). (7) The length of time spent with moderate intensity PA. (8) The length of time spent with vigorous intensity PA. (9) Length of time spent with very vigorous intensity PA, (10) Length of time in moderate to vigorous physical activity (MVPA), (11) Total step counts, (12) Total activity counts and counts per minute (cpm) with three-axial motions (vertical, anterior-posterior and mediolateral), (13) Vector magnitude (VM) calculated through the square root of the sum of squares of cpm from all three axes, and vector magnitude cpm.

We validated the index against the following participant-reported variables: (A) Do you make physical activity? (1) I do not do physical activity and do not want to do. (2). I do not do physical activity, but I want to. (3) I do physical activity, but not all or almost every day. (4) I do physical activity most days of the week, but that is a learned behavior for less than six months. (5) I do physical activity most days of the week, and that's a learned behavior for more than six months. To simplify handling this variable, we re-categorized it into three classes as follows: (1) No, (2) Sometimes, and (3) Yes. (B) For how long do you make light physical activity? (C) For how long do you make moderate physical activity? (D) For how long do you make vigorous physical activity? Questions B-D were presented with the same seven response options: (1) None. (2) 0.5 hour-2 hours per week. (3) 2.5-3 hours per week. (4) 3.5-4 hours per week. (5) 4.5-5 hours per week. (6) 5.5-6 hours per week. (7) More than 7 hours a week. (E) Indicate the answer that best describes you. I dedicate part of my day to physical activity: Never / rarely (0), sometimes (1), often (2).

Our exploratory analysis started by evaluating distributions, frequencies, and percentages for each of the numeric and categorical variables. Categorical variables were evaluated for near-zero variation (Kuhn e Johnson, 2013). Extensive graphical displays were used for both univariate analysis and bivariate associations, accompanied by broader tests such as Maximal Information Coefficient (RESJEF et al., 2011) and Nonnegative Matrix Factorization (PAATERO E TAPPER, 1994) algorithms for numeric variables. Missing data were explored using a combination of graphical displays involving univariate, bivariate and multivariate methods. Imputation was performed using a k-nearest neighbors algorithm $(n=5)$ (PRANTNER, 2011).

As part of the exploratory analysis, we used correlation matrices and plots to understand the existing association across all items better. Since items were numeric, ordinal and logical, we made use of Pearson, Polychoric and Polyserial correlation tests where appropriate. Next, we conducted a series of exploratory factor 
analyses using a variety of oblique and orthogonal rotations to understand better the factors underlying the data. The evaluation of factor solutions used a variety of metrics and heuristics including scree plots, looking for solutions that were theoretically justifiable and choosing solutions where an item would have a loading above 0.30 while all other items were below zero.

Once we defined the primary constructs, we normalized each item as well as the summed score for each construct to a 0-100 score. Each score was also evaluated regarding internal reliability. Finally, validity was assessed with self-reported variables.

The self-reported variables included: General physical activity habits, daily time spent in light physical activity, daily time spent in moderate physical activity, time spent in vigorous physical activity, and time expended in any form of physical activity. All analyses were performed using the $\mathrm{R}$ language and the following packages: ggplot2, rmarkdown, and lavaan.

\section{RESULTS}

Out of the original 270 subjects in the trial, 75 were excluded for lack of devices for a school, missing the orientation day when devices were distributed, and training was performed, or data loss during data extraction from the accelerometer device.

The initial analysis presents an overall study sample description along with a stratification by socioeconomic status. The study population comprised 195 adolescent females with an average age of $13.4+-0.65$ years. A total of $20.5 \%$ of them were overweight, $10.8 \%$ obese, and $51 \%$ physically inactive. After categorizing baseline variables according to socio-economic class, we observed that participants in a medium-high class presented higher rates of no physical activity habits compared to subjects in medium-low class group ( $56.5 \%$ vs. $48 \%$ ). The participants in medium-low class presented higher METs [1.03 (+- 0.03)]. Most of the medium-low class participants spent daily half an hour to two hours per week in light and vigorous physical activity, with $25 \%$ and $28 \%$, respectively. All participants dedicated their part of day to physical activity (Table 1).

Table 1: Patient sample baseline characteristics categorized by socio-economic classes.

\begin{tabular}{|c|c|c|c|c|}
\hline Variable [Missing] & Total (195) & $\begin{array}{l}\text { Medium-high } \\
\text { class }(70)\end{array}$ & $\begin{array}{l}\text { Medium-low } \\
\text { class (125) }\end{array}$ & p-value \\
\hline Age [0] & $13.4( \pm 0.65)$ & $13.4( \pm 0.66)$ & $13.4( \pm 0.64)$ & 0.564 \\
\hline “BMI [0] & $21.1( \pm 4.29)$ & $21( \pm 4.76)$ & $21.1( \pm 4.03)$ & 0.838 \\
\hline \multicolumn{4}{|l|}{ BMI percentile category [0] } & \multirow{5}{*}{0.384} \\
\hline - Underweight or at risk (<P15) & $20(10.3 \%)$ & $10(14.3 \%)$ & $10(8.0 \%)$ & \\
\hline - Eutrophic (P15-P85) & $114(58.5 \%)$ & $41(58.6 \%)$ & $73(58.4 \%)$ & \\
\hline - Overweight (P85-P97) & $40(20.5 \%)$ & $10(14.3 \%)$ & $30(24.0 \%)$ & \\
\hline -Obesity $(P>97)$ & $21(10.8 \%)$ & $9(12.9 \%)$ & $12(9.6 \%)$ & \\
\hline \multicolumn{4}{|l|}{ Habits physical activity [1] } & \multirow{4}{*}{0.314} \\
\hline - No & $99(51 \%)$ & $39(56.5 \%)$ & $60(48 \%)$ & \\
\hline - Sometimes & $61(31.4 \%)$ & $17(24.6 \%)$ & $44(35.2 \%)$ & \\
\hline - Yes & $34(17.5 \%)$ & $13(18.8 \%)$ & $21(16.8 \%)$ & \\
\hline${ }^{*}$ METs [0] & $1.03( \pm 0.03)$ & $1.02( \pm 0.02)$ & $1.03( \pm 0.03)$ & 0.009 \\
\hline \multicolumn{4}{|c|}{ Daily time spent in light physical activity [175] } & \multirow{5}{*}{0.198} \\
\hline - None & $14(70 \%)$ & $10(83.3 \%)$ & $4(50 \%)$ & \\
\hline - 0.5 hour- 2 hours per week & $2(10 \%)$ & $0(0 \%)$ & $2(25 \%)$ & \\
\hline - 2.5-3 hours per week & $2(10 \%)$ & $1(8.3 \%)$ & $1(12.5 \%)$ & \\
\hline $\begin{array}{l}\text { - } 3.5-4 \text { hours per week } \\
-4.5-5 \text { hours per week }\end{array}$ & $\begin{array}{l}1(5 \%) \\
1(5 \%)\end{array}$ & $\begin{array}{c}1(8.3 \%) \\
0(0 \%)\end{array}$ & $\begin{array}{c}0(0 \%) \\
1(12.5 \%)\end{array}$ & \\
\hline
\end{tabular}


Table 1 (continuing)

\begin{tabular}{|c|c|c|c|c|}
\hline Variable [Missing] & Total (195) & $\begin{array}{l}\text { Medium-high } \\
\text { class }(70)\end{array}$ & $\begin{array}{l}\text { Medium-low } \\
\text { class (125) }\end{array}$ & p-value \\
\hline \multicolumn{4}{|c|}{ Daily time spent in moderate physical activity [54] } & \multirow{7}{*}{0.319} \\
\hline - None & $130(92.2 \%)$ & $49(96.1 \%)$ & $81(90 \%)$ & \\
\hline - 0.5 hour- 2 hours per week & $3(2.1 \%)$ & $1(2 \%)$ & $2(2.2 \%)$ & \\
\hline - 2.5-3 hours per week & $3(2.1 \%)$ & $0(0 \%)$ & $3(3.3 \%)$ & \\
\hline - 3.5-4 hours per week & $2(1.4 \%)$ & $0(0 \%)$ & $2(2.2 \%)$ & \\
\hline - 4.5-5 hours per week & $2(1.4 \%)$ & $0(0 \%)$ & $2(2.2 \%)$ & \\
\hline - 5.5-6 hours per week & $1(0.7 \%)$ & $1(2 \%)$ & $0(0 \%)$ & \\
\hline \multicolumn{4}{|c|}{ Daily time spent in vigorous physical activity [152] } & \multirow{6}{*}{0.415} \\
\hline - None & $19(44.2 \%)$ & $7(38.9 \%)$ & $12(48 \%)$ & \\
\hline - 0.5 hour-2 hours per week & $11(25.6 \%)$ & $4(22.2 \%)$ & $7(28 \%)$ & \\
\hline - 2.5-3 hours per week & $8(18.6 \%)$ & $3(16.7 \%)$ & $5(20 \%)$ & \\
\hline - 3.5-4 hours per week & $2(4.7 \%)$ & $2(11.1 \%)$ & $0(0 \%)$ & \\
\hline - 5.5-6 hours per week & $3(7 \%)$ & $2(11.1 \%)$ & $1(4 \%)$ & \\
\hline \multicolumn{4}{|c|}{ I dedicate part of my day to physical activity [116] } & \multirow{3}{*}{1} \\
\hline - Sometimes & $53(67.1 \%)$ & $21(67.7 \%)$ & $32(66.7 \%)$ & \\
\hline - Often & $26(32.9 \%)$ & $10(32.3 \%)$ & $16(33.3 \%)$ & \\
\hline
\end{tabular}

"MET (metabolic equivalent), ${ }^{*}$ BMI (Body Mass Index). Source: Data Search, 2018.

Figure 1 - Correlation matrix.

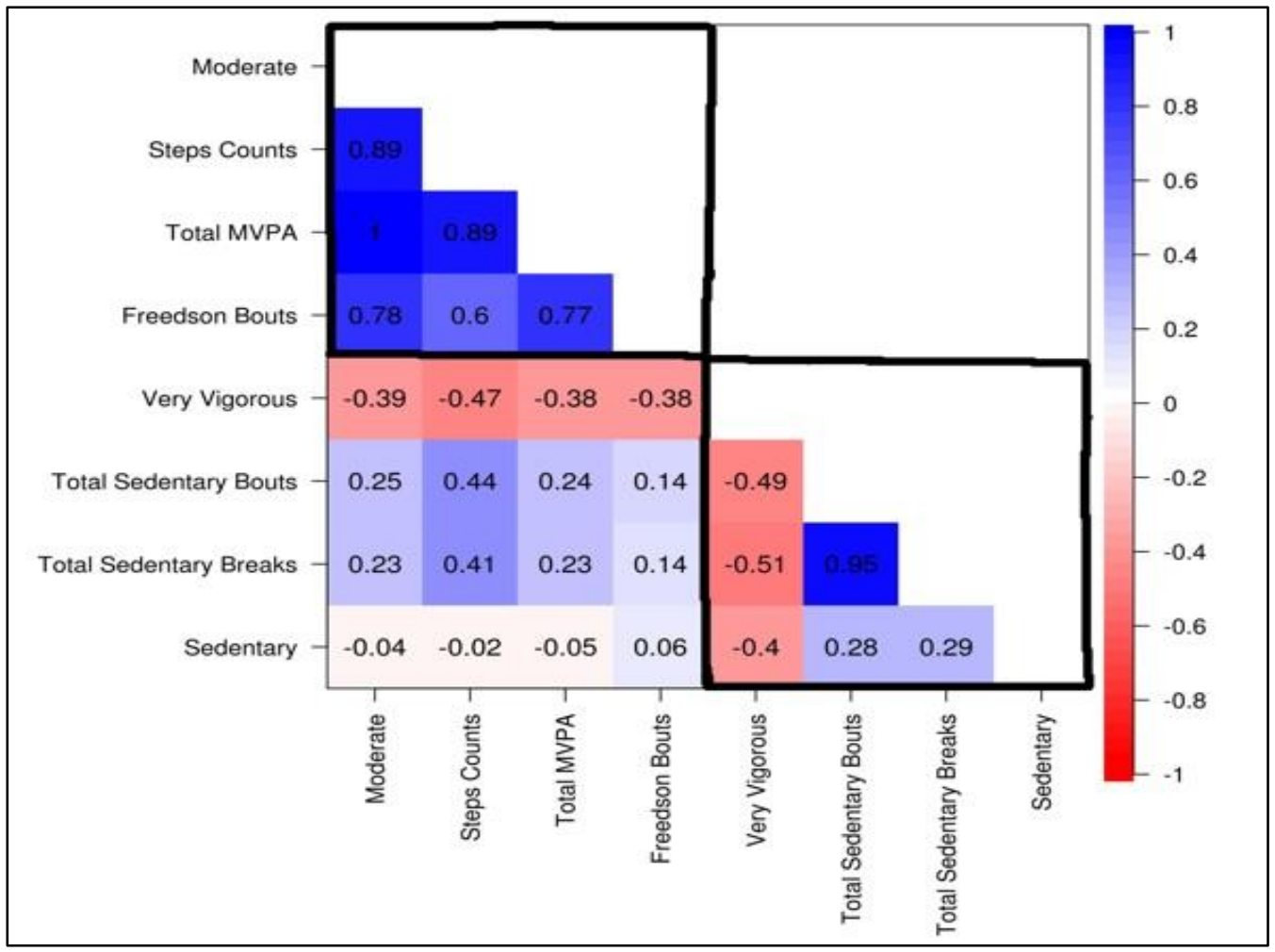

Labels: MVA (moderate-to-vigorous physical activity), MET (metabolic equivalent). Source: Data Search, 2018. 
With a correlation matrix, two large variable clusters were identified by colors with a darker hue. The first was associated with physical activity and included moderate activity, many steps, total MVPA, and Freedson bouts. The second was related to sedentary activity and included the total number of sedentary breaks, total number of sedentary bouts, sedentary activities, and very vigorous activities. In this plot, the red color indicates that the cluster was negatively associated with the central theme. For example, very vigorous activities were negatively associated with the Sedentary Activity cluster (Figure 1).

These findings were then validated through an Exploratory Factor Analysis where the same items presented a loading pattern across two factors, labeled Daily Physical Activity and Sedentary Activity. Items loading on each of the two factors presented a loading above 0.3 (see loadings in bold), while the loading on the other factor was below that level (Table 2).

Both factors presented acceptable reliability indices as measured through Raw Cronbach's Alpha, Standardized Alpha and Guttman's Lambda 6 indices (Table 3), with all indices presenting values above 0.7.

Table 2: Exploratory factor analysis with two factor loadings

\begin{tabular}{l|c|c}
\hline & Daily Physical Activity & Sedentary Activity \\
\hline Moderate activities & $\mathbf{1 . 0 1 0 8}$ & -0.0375 \\
\hline Total MVPA & $\mathbf{1 . 0 0 9 3}$ & -0.0477 \\
\hline Number of steps & $\mathbf{0 . 8 3 1 3}$ & 0.2010 \\
\hline Freedson Bouts & $\mathbf{0 . 7 8 4 8}$ & -0.0450 \\
\hline Total Sedentary Bouts & -0.0032 & $\mathbf{0 . 9 4 8 1}$ \\
\hline Total Sedentary Breaks & -0.0173 & $\mathbf{0 . 9 5 7 0}$ \\
\hline Sedentary activities & -0.1279 & $\mathbf{0 . 4 0 5 6}$ \\
\hline Very Vigorous activities & -0.2800 & $\mathbf{- 0 . 5 0 5 4}$ \\
\hline
\end{tabular}

Labels: MVPA (moderate-to-vigorous physical activity), MET (metabolic equivalent). Source: Data Search, 2018.

Table 3: Alpha values of confirmatory factor analysis

\begin{tabular}{lcccc}
\hline & $\begin{array}{c}\text { Raw } \\
\text { Alpha }\end{array}$ & $\begin{array}{c}\text { Standardized } \\
\text { Alpha }\end{array}$ & $\begin{array}{c}\text { Guttman's } \\
\text { Lambda 6 }\end{array}$ & $\begin{array}{c}\text { Interitem } \\
\text { correlation }\end{array}$ \\
\hline Daily Physical Activity & 0.948 & 0.948 & 0.961 & 0.819 \\
\hline Sedentary Activity & 0.79 & 0.79 & 0.828 & 0.485 \\
\hline Source: Data Search, 2018. & & & & \\
\hline
\end{tabular}

Source: Data Search, 2018. 
Once both factors on Daily Physical Activity and Sedentary Activity were completely evaluated, we proceeded to validate their corresponding median score changes between baseline and nine weeks into the program against other metrics of physical activity habits. The final normalized score was calculated using the following formula: $x^{\prime}=x-\min (x) / \max (x)-\min (x)$, where $x$ is an original value, $x^{\prime}$ is the normalized value. For example, participants' physical activity habit data ranges from one to five. The normalized score is calculated as follows: First, subtract one from each participant's physical activity habit data and divide the result by four (which is the difference between the maximum and minimum score). We found that the daily physical and sedentary activity scores were significantly associated with METs ( $p$ values of 0.005 and 0.04 , respectively). Sedentary activity score demonstrated a significant association with self-reported light physical activity $(p=$ 0.014).

\section{DISCUSSION}

To the best of our knowledge, this is the first validation of an Accelerometer Index focused on adolescent girls in a Latin American environment. Our results demonstrate a two-factor structure, with good factor loadings and internal reliability scores, as well as appropriate validity across a range of self-reported physical activity measures.

Both the Daily Physical Activity and Sedentary Activity scores were significantly associated with selfreported scores of physical activities. These results are in line with previous studies involving smaller sample sizes, finding a positive association between measures of physical activity using accelerometers and selfreport measures (CORDER et al.,2009; HALLAL et al.,2013). Previously reported strengths of correlations expressed as rho coefficients ranged from 0.24 to 0.63 , while validity was established through a series of statistically-significant measures in our study. This discrepancy likely results from a stricter psychometric approach used in our study, where we have followed exploratory methods, the measurement of internal reliability and validation tests (TROST et al., 2011).

The validity of our scale was present in both high and low levels of physical activity. Although some authors determined that this validity might not be influenced by activity levels (DENCKER e ANDERSEN, 2011), other studies found the opposite effect (JANZ et al., 2008; PHILIPPAERTS et al, 2006;). The reason for this divergence may be related to how physical activity is measured, including the assessment or not of maximum oxygen uptake (JANZ et al., 2008; DENCKER e ANDERSEN, 2011). Recall bias is yet another potential reason since more vigorous activities are more accurately remembered and more readily captured through accelerometers.

We found no effect of age on the strength of the correlation between the accelerometer and self-reported data. Some studies have reported validity for the Youth Physical Activity Questionnaire among 12-14-year-old adolescents but not among older individuals (CORDER et al, 2009). Others have reported an increased strength in the correlation proportional to adolescence (DÖSSEGGER et al., 2014), which may be explained by changes in behavior due to the awareness of being measured (MOTL et al., 2012). Previous reports demonstrated that this response is more important at the beginning of trials (DÖSSEGGER et al., 2014).

Our results present several strengths, the analytic methodology constituting one of them. Selecting a cutoff point for accelerometer parameters is challenging because different studies have identified multiple values (PULSFORD et al.,2011). In fact, these cut-off points have been tested for performance (TROST et al., 2011), which is not trivial since the selection of cut-off points for this measurement influences the recommendation of activity levels in children (GÁBA et al., 2016). Our approach enabled us to overcome these barriers through the generation and validation of a novel accelerometer index providing a continuous metric. Another strength of our results is that we made use of a broad cross-section of 10 schools including participants from several minority groups, ultimately making it more generalizable. Using data from both questionnaires and accelerometers can alleviate the pitfalls from each source, rendering information easier to translate into actionable knowledge. This mixed-methods approach enabled the interpretation of programs relying on physical activity as an intervention. 
Although our study brings novelty to the literature, there are limitations. First, we did not include other objective measurements of physical activity such as maximum oxygen uptake, as it would have been challenging to apply this technique in the context of a school-based clinical trial focused on behaviors related to food and physical activity. Also, prior research did not identify an association between self-reported information and maximum oxygen uptake. Second, laboratory measures are difficult to establish in a schoolbased randomized trial with a large number of participants, and therefore the measurements proposed in our study might not be feasible in larger, pragmatic studies. Third, our data comes from a randomized controlled trial with a controlled experiment. Although this guarantees better data quality, participants outside such studies might be less compliant, introducing challenges to measurement validity. Last, accelerometer technologies are constantly evolving, and so indices relying on ever changing, more advanced technologies might have results that differ from ours. Although this is a limitation, we believe that with an increased ease of use it is likely that the psychometric properties related to other devices should improve rather than deteriorate.

\section{CONCLUSION}

Our validated indices could be used to test the efficacy of exercise interventions since they can serve as an objective measure of change and adherence to behaviors connected to physical activity. Another application of our indices will be to calibrate current levels of physical activity in particular contexts. Moreover, our indices will impact the categorization of adolescents as active or inactive, a significant risk factor for an increasing number of diseases that affect adolescents, as well as self-esteem and mental health in general.

\section{ACKNOWLEDGMENTS}

The authors thank Centro de Estudos do Laboratório de Aptidão Física de São Caetano do Sul (CELAFISCS) for borrowing the accelerometers for the development of the study.

This work was supported by the São Paulo Research Foundation (FAPESP) [grant number2012/16952-8]; and by the Brazilian National Council for Scientific and Technological Development (CNPQ) [grant number 483871/2013-3].

\section{REFERENCES}

1. ABEP. Associação Brasileira de Empresas de Pesquisa. (2011). Critério de classificação econômica Brasil. http://www.abep.org/novo/Content.aspex?ContentID=301.

2. BECKER KT, COSTA MJ, LESSA AH et al. Test in school children aged between 7 and 10 from two dissimilar socioeconomic cultural backgrounds. Arq Int Otorrinolaringol, 2011;15(3):338-45.

3. CORDER K, SLUIJS EM VAN, WRIGHT A et al. Is it possible to assess free-living physical activity and energy expenditure in young people by self-report? Am J Clin Nutr 2009; 89(3):862-70.

4. DENCKER M, ANDERSEN LB. Accelerometer-measured daily physical activity related to aerobic fitness in children and adolescents. J Sports Sci, 2011; 29(9):887-95.

5. DÖSSENGER A, RUCH N, JIMMY G et al. Reactivity to Accelerometer Measurement of Children and Adolescents. Med Sci Sports Exerc 2014; 46(6):1140-6.

6. DUNKER KLL, CLAUDINO AM. Preventing weight-related problems among adolescent girls: A cluster randomized trial comparing the Brazilian 'New Moves' program versus observation. Obes Res Clin Pract 2018; 12(1),102-115.

7. DUMITH SC, GIGANTE DP, DOMINGUES MR et al. Physical activity change during adolescence: A systematic review and a pooled analysis. Int J Epidemiol 2011; 40(3):685-98.

8. DYRSTAD SM, HANSEN BH, HOLME IM et al. Comparison of self-reported versus accelerometer-measured physical activity. Med Sci Sports Exerc 2014;46(1):99-106. 
9. GÁBA A, DYGRÝN J, MITÁŠ J etc. Effect of Accelerometer Cut-Off Points on the Recommended Level of Physical Activity for Obesity Prevention in Children. PLoS One 2016; 11(10):e0164282.

10. HALLAL PC, REICHERT FF, CLARK VL et al. Energy Expenditure Compared to Physical Activity Measured by Accelerometry and Self-Report in Adolescents: A Validation Study. PLoS One 2013; 8(11), e77036.

11. HEATH GW, PARRA DC, SARMIENTO OL et al. Evidence-based intervention in physical activity: Lessons from around the world. Lancet,2012;380(9838):272-81.

12. HOLLIS JL, SUTHERLAND R, WILLIAMS AJ et al. A systematic review and meta-analysis of moderate-to-vigorous physical activity levels in secondary school physical education lessons. Int J Behav Nutr Phys Act 2017; 14(1):52.

13. JANZ KF, LUTUCHY EM, WENTHE $P$ et al. Measuring activity in children and adolescents using self-report: $P A Q-C$ and $P A Q-A$. Med Sci Sports Exerc, 2008; 40(4):767-72.

14. KUHN M, JOHNSON K. Applied predictive modeling. Vol. 810. (pp. 30-32).New York: Springer; 2013.

15. LEE IM, SHIROMA EJ. Using Accelerometers to Measure Physical Activity in Large-Scale Epidemiologic Studies: Issues and Challenges. Br J Sports Med 2014; 48(3):197-201.

16. LONEY T, STANDAGE M, THOMPSON D et al. Self-report vs. objectively assessed physical activity: Which is right for public health? J Phys Act Health, 2011; 8(1):62-70.

17. MOTL RW, MCAULEY E, DLUGONSKI D. Reactivity in baseline accelerometer data from a physical activity behavioral intervention. Health Psychol 2012;31(2):172-5.

18. PAATERO P, TAPPER U. Positive matrix factorization: A non-negative factor model with optimal utilization of error estimates of data values. Environmetrics 1994; 5(2): 111-26.

19. PHILIPPAERTS RM, MATTON L, WIJNDAELE K et al. Validity of a Physical Activity Computer Questionnaire in 12- to 18-year-old Boys and Girls. Int J Sports Med, 2006; 27(2),131-6.

20. PRANTNER B. Visualization of imputed values using the r-package vim, 2011.

21. PRINCE SA, ADAMO KB, HAMEL ME et al. A comparison of direct versus self-report measures for assessing physical activity in adults: A systematic review. Int J Behav Nutr Phys Act 2008; 5:56.

22. PULSFORD RM, CORTINA-BORJA M, RICH C et al. Actigraph Accelerometer-Defined Boundaries for Sedentary Behaviour and Physical Activity Intensities in 7 Year Old Children. PLoS One 2011; 6(8): e21822.

23. RESHEF DN, RESHEF YA, FINUCANE HK et al. Detecting novel associations in large data sets. Science, 2011; 334(6062):151824.

24. TODD AS, STREET SJ, ZIVIANI J et al. Overweight and Obese Adolescent Girls: The Importance of Promoting Sensible Eating and Activity Behaviors from the Start of the Adolescent Period. Int J Environ Res Public Health 2015;12(2):2306-29.

25. TROIANO RP, PETTEE GABRIEL KK, WELK GJ et al. Reported physical activity and sedentary behavior: Why do you ask? J Phys Act Health,2012; 9(Suppl 1), S68-75.

26. TROST SG, LOPRINZI PD, MOORE R et al. Comparison of accelerometer cut points for predicting activity intensity in youth. Med Sci Sports Exerc 2011; 43(7):1360-8.

27. VANDER WAL JS. Unhealthy weight control behaviors among adolescents. J Health Psychol 2012; 17(1):110-20.

28. VON ELM E, ALTMAN DG, EGGER M et al. The strengthening the reporting of observational studies in epidemiology (strobe) statement: Guidelines for reporting observational studies. BMJ 2007; 335(7624):806-8. 